\title{
THE GREAT “AUTO DE FE” AT SANTIAGO DE LOS CABALLEROS, OR HOW TO ACHIEVE HISTORICAL EMPATHY WITH CULTURAL HERITAGE THROUGH VIRTUAL REALITY
}

\author{
A. Rodriguez ${ }^{1 *}$, J. F. Chuchiak ${ }^{2}$, H. B. Erickson ${ }^{3}$, P. V. Ballicu ${ }^{1}$ \\ ${ }^{1}$ Universidad Anahuac Mayab, School of Architecture, 97310 Mérida Yucatán, México - (antonio.rodriguez, \\ 00267267)@anahuac.mx \\ ${ }^{2}$ Missouri State University, Honors College, 901 S. National Ave., Springfield, Missouri, USA - john.chuchiak@ missouristate.edu \\ ${ }^{3}$ Missouri State University, Digital Cultural Preservation Program, 901 S. National Ave., Springfield, Missouri, USA, \\ hans065@live.missouristate.edu
}

KEY WORDS: Virtual Museums, Virtual Reality, Guatemala, Auto de Fe, Unreal Engine

\begin{abstract}
:
The project "The Great Auto de Fe in Santiago de los Caballeros" consisted of an interactive virtual recreation of this historical event that occurred on March 11, 1554 in the city today known as Antigua, Guatemala. A binational research team from Mexico and the U.S. made up of historians, architects and animation engineers, in the space of five weeks, created the historical settings, characters and interactivity necessary to offer the public this immersive experience. The project was presented within the framework of an international exhibition "The images of the Maya gods in the 16th century: The meeting of two worlds," located at the Centro de Formación para la Cooperación Española in Antigua, the site of a former $17^{\text {th }}$ century Jesuit College. This article presents the details of the workflow used, the social and cultural implications observed, as well as the results of the satisfaction surveys applied to approximately $80 \%$ of the users who had access to this experience.
\end{abstract}

\section{INTRODUCTION}

\subsection{Concepts Still Under Review}

The state of art that dominates the field of virtual applications is extremely fluid these days, even more so in the case of such applications in relation to the preservation of Cultural Heritage. The degree of advancement of these technologies is allowing forms of interaction with cultural objects never seen before, allowing for a deeper level of understanding, while reaching more audiences and which together constitute an experience not only of knowledge but of the internalization of the value and importance of Cultural Heritage.

Due to the new features that arise practically every day in the field and their almost immediate application possibilities (without a learning curve) to cultural objects, it is difficult to establish benchmarks or conceptual foundations from which to define the best modalities or practices for presenting and disseminating Cultural Heritage to the public with the premise that digital media offer advantages over traditional ones in terms of their means of dissemination and spread of knowledge. It would be limiting to consider that digital media are just "one more tool" or a complementary element, when in fact they have the ability to comprise and configure the entire museum discourse. In short, it we are talking about a theoretical corpus still in formation.

From previous experiences we wish to postulate that the use of virtual worlds should be, first of all, an educational strategy. Documents such as the London Charter $(2009,5)$ establish that project development communities in these experiences can be academic, educational, curatorial or commercial; however, the aspect of the communication of the values studied should be evident throughout the project. We consider, on the other hand, that it is important that any such project must involve both knowledge and emotions that facilitate meaningful learning in users. Santacana and Martínez (2016, 3), mentioning YerkesDodson $(1908,459)$, establish that there is a clear relationship between emotional arousal and learning, both in a direct and inverse sense: the greater the excitement, the greater the learning and vice versa. Graphically it would be an inverted letter "U" or graph, in which, the more emotion, the more learning, reaching an optimum or maximum point from which, if the emotion continues to increase, the learning decreases.

In this sense, heritage is an educational tool, since it contains a high potential for emotionality. In an ideal emotional and learning flow, the perception of heritage is directly related to the viewer's understanding. Understanding can lead to empathy, which is, feeling emotional identification with something or someone. Ergo, improving the perception of a cultural object can directly lead to empathy for it.

Another significant concept is Inclusive Cultural Heritage. Many Cultural Heritage sites are not de facto accessible to certain audiences, due to diverse circumstances such as architectural or topographic barriers (Rufino, Permadi et al., 2019,144), or the same conditions of conservation of the cultural object or site do not allow accessibility for the public. Digital media can dilute these barriers and even improve the existing or possible mobility for the viewer to interact and learn about heritage from unprecedented angles, contributing to the aforementioned improvement in perception, not to mention the feeling of inclusion, beneficial for users even before knowing about the educational purpose of the model.

A third concept is that of Spatial History (White, 2010): a complementary paradigm to traditional history, which tends to focus on time, by a new one based on an analysis of space. Its

\footnotetext{
* Corresponding author
} 
premise is that history is better known by living it through space, since it will involve more senses and sensations than just the analysis of traditional texts.

It is interesting to note that, with all the advantages it offers, Spatial History, or spatial visualizations in general, do not necessarily guarantee cognitive spatial internalization in the user: this can take time to form (Chiarenza, Accardi and Inglisa, 2019, 314). It is necessary to use a graduated spatiality for the different types of users, presenting it previously, for example, in a presensitization room for the museo-graphic exhibition.

Virtual Museums (VM) are still considered today as a complement or "digital footprint" of the physical museum (Shim, Jun and Ahn, 2019: 1090), however the trend is that they can act more independently, even developing their own curatorial parameters. The educational, simulative and playful factors of a VM (Aiello, Fai and Santagati, 2019, 34), can be enriched with the emotional component. At a more operational level, interactivity and surprise factors are essential to achieve user attraction (Santacana and Martínez 2016, 6), and thus favor their empathic capacity.

\subsection{Proposed Taxonomy}

Given the myriad of conceptual considerations necessary regarding the historical record / recreation models, we proposed a simplification - derivation: the use of Syntagma Models (purposely ordered sets of elements) which leads to Ontological, or rather Discursive Models (with expressly designed existence and purpose) to generate a Semantic (interpretive) reaction in a certain group of users, who will validate the relevance of the models through their reactions in situ to the model with their subsequent feedback being essential for closing the cycle. In this sense, the ontological variety of the pieces can at first be confusing for the spectator who walks through the museum stage, since they could come across moving pieces, pieces that seek interactivity to make themselves known, or pieces that must be analyzed, taxonomically dismembered (Pavelka and Raeva, 2019,903 ), or even the viewer's own kinesics could determine the quality of what is presented.

In a more inclusive effort to the concepts already mentioned, what we wish to propose is, more than a VM, a Historically Reconstructed Scenario (HRS), which can integrate pieces of a Virtual Museum, but these are no longer static, but dynamic, transformable, and if the museum program proposes it, they can be "controllably unpredictable," incorporating the surprise factor mentioned above. An attraction - empathetic reaction, both cognitive and emotional on the part of users, is the highest objective of a Scenario. The axis of work for the project to achieve this objective include:

- Emotion

- Surprise

- Specific design of interactivity through Discursive Models

- Inclusion of accessibility

- Inclusion of focused content for different users

${ }^{1}$ Testimonio del Dr. Diego de Quijada, Alcalde Mayor, sobre el auto público que se celebró en contra de los idólatras, 1565 , AGI, Patronato 184, Ramo 52.

${ }^{2}$ Testimonio de Fray Antonio Quijada sobre el auto público de los indios idolatras, 1565, AGI, Escribanía de Cámara, 1009A, 3 folios

\section{- $\quad$ Recording of reactions, feedback and follow-up}

In this way, a product oriented entirely to the user is configured, which must be monitored in detail, both in its reactions "on the go" while the viewers experience the Scenario, as well as in its subsequent feedback through satisfaction surveys and other monitoring tools.

\section{THE AUTO DE FE OF 1554}

\subsection{The "Spiritual Conquest" and the Destruction of the physical objects and god images of the Maya}

On Sunday, March 11, 1554, in the central square of the City of Santiago de los Caballeros de Guatemala, Bishop Francisco Marroquín gathered all the people to participate in a great public auto de fe (act of faith) to witness the sentences and punishments issued against almost a hundred Maya Indians accused of idolatry. Many of the Quiche, Kaqchikel, Mam and Tztujil Maya were forcibly brought in that Sunday of Lent from distant provinces far from the capital of Guatemala. Among those who would receive punishment were community leaders and nobles, including members of the Maya elite and nobility of Quetzaltenango, Comalapa, Chichicastenango, Huehuetenango and other towns.

Bishop Marroquín, dressed in accordance with the pontifical protocol, with his miter and crozier, preceded to direct one of the greatest autos-da-fé against the natives of the new world. With the help of an army of religious interpreters who translated his words into more than five indigenous languages, Marroquín took the pulpit and delivered a speech of reprimand to the penitent indigenous people. After this speech, the bishop gave orders for three friars of the three most important religious orders in the kingdom of Guatemala, the Franciscans, Dominicans and Mercedarians, to come forward to "preach certain sermons to the Indians in their languages detesting and abhorring their crime and the offense they had done to Our Lord God."1

Following his speech, a Dominican friar preached another Kaqchikel-language sermon against idolatry, followed by a Mercedarian friar's speech in Mam. According to Fray Antonio Quijada, who witnessed the event, there was "a great fire in the square of said city in front of the main church" and the friars in their sermons were "threatening the Indians saying that they deserved to be burned there alive." 2 To achieve a greater dramatic effect, the religious and the members of the Royal Audiencia court agreed in advance to fake an attempted burning of some of the indigenous people just so that the friars could offer their prayers, entreaties and beg for mercy for the rest of the condemned "idolaters." To continue with the farce, the oidor, or judge, Licenciado Pedro Ramírez de Quiñones "came down [...] and took two or three Indians from the idolaters saying that he wanted to burn them in the fire and the friars of San Francisco and Santo Domingo took them away begging that their mercy did not do that promising him they would make amends."3

The event continued with the reading of the sentences for the $a j^{\prime} q^{\prime} i j$, or Mayan priests, the caciques, and the members of the indigenous councils who were accused of being idolaters. All

${ }^{3}$ Testimonio del fraile dominico, Fray Diego de la Cruz, sobre los autos de fe para indios, 23 de enero, 1565, AGI, Patronato 184, Exp. 52, 4 folios 
were forced to carry "ropes around their necks and others work the pointed corozas [dunce-caps of shame]," and they had thier heads shaved and were flogged as punishment. Others, on the other hand, "were sentenced to a certain time of servitude to the church and in a certain amount of money, and to pay the costs of their trials, as well as appear in penance before a mass in church with ropes around thier necks and naked from the waist up." ${ }^{4}$ As they read their sentences the great bonfire continued to burn, and the officers ordered the penitent defendants to throw their own gods into the fire. To receive their sentence and punishment, the defendants wore corozas and sanbenitos painted with shapes of "demons and devils" and other figures that witnesses to the event described as "very ugly." Each of the penitent Maya came down from the platform to throw their idols and other sacred objects onto the pyre, all of them accompanied by a designated prosecutor or bailiff.

The public auto de fe celebrated by Bishop Marroquín was interpreted as the triumph of the Catholic faith over the traditional indigenous religion; however, this was only a short-lived success in their attempt to confront and punish indigenous religious practices. Mayan resistance to the so-called "spiritual conquest" continued despite persecution. As a result, the religion and religious practices of the Maya resisted the extirpation of "idolatries," and instead survived, allowing the preservation and growth of indigenous popular religions, to which many Mayas integrated elements of the Catholic religion in open appropriation. The Mayas of Guatemala preserved a large number of their beliefs, traditional practices, and even preHispanic rites and ceremonies, which they continued to practice openly, despite the fear of being punished rigorously.

\section{THE VIRTUAL RECREATION PROJECT OF THE AUTO DE FE}

\subsection{The Method: Known Tools and ad hoc Work Dynamics}

Remote collaborative work schemes are today the most efficient way to integrate teams from different latitudes and expertise, with the advantages of quality, economy and efficiency that it entails. As this was a project that integrated an international team of specialists, synchronous communication was essential to complete the project with a very short deadline and this was the first thing to be established, even before the technical pipeline. Instant communication channels were established for short messages, as well as video-meets for work sessions, presenting progress or making agreements. Although the work was fully developed in the pre-pandemic era, it would not have been much different had this occurred.

The transdisciplinary nature of the project required a holistic and systemic approach which imposed a workflow in which each actor could participate at any moment of development, even after having concluded their contribution. By placing the Unreal Engine $^{\odot}$ (UE) software as the final integrator program, all historical research, architectural work, model development and museum development operations converged on creating validated products that became part of the VR World in UE.

Schematically, four work teams were organized:

1. An Architectural team, which developed the architecture of the Main Square of Santiago de los Caballeros, the scene of the Great

${ }^{4}$ Testimonio del notario del juzgado episcopal, Alonso de Rojas, sobre los autos de fe para los indios celebrados por el obispo Francisco de Marroquín, 18 de mes de Marzo, 1563, AGI, Escribanía de Cámara, 1009ª 6 folios.
Auto of 1554. A sub-team was in charge of the design of the staging of the platforms for Spanish authorities, since there were documents that accurately described these elements (Figure 1).

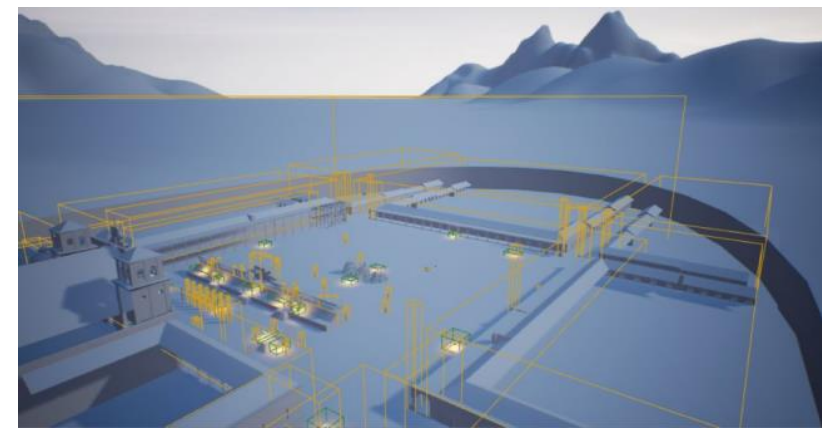

Figure. 1. Main Square of Santiago de los Caballeros, Guatemala, 1554. Unreal Engine, blocking boxes view.

2. An Historical Team, which provided and analyzed the historical documents describing what happened that day, as well as providing access to the historical pieces that were going to be exhibited, and their photogrammetric products (Figure 2).

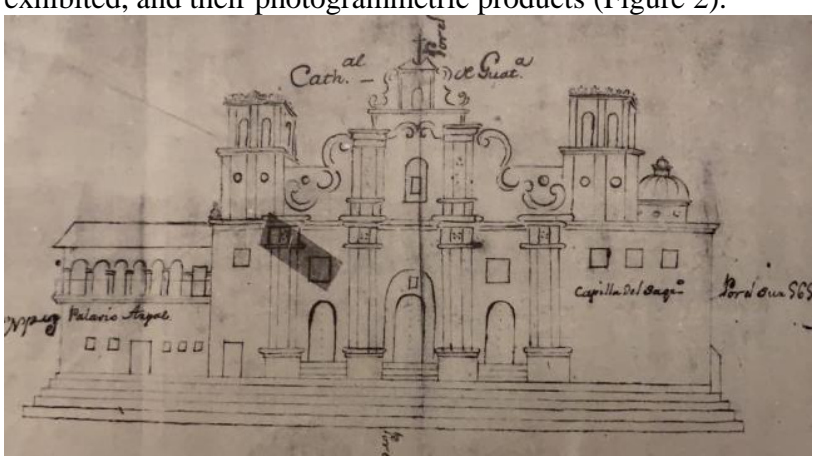

Figure. 2. Archival image of the 17th century facade of the Cathedral of Santiago de los Caballeros, which was the basis for architectural modeling. Image provided by the Historical Team.

3. A Game Development Team, which integrated all the information in the VR scenario, modeled characters, particles, optimized polygons (Figures 3, 4).

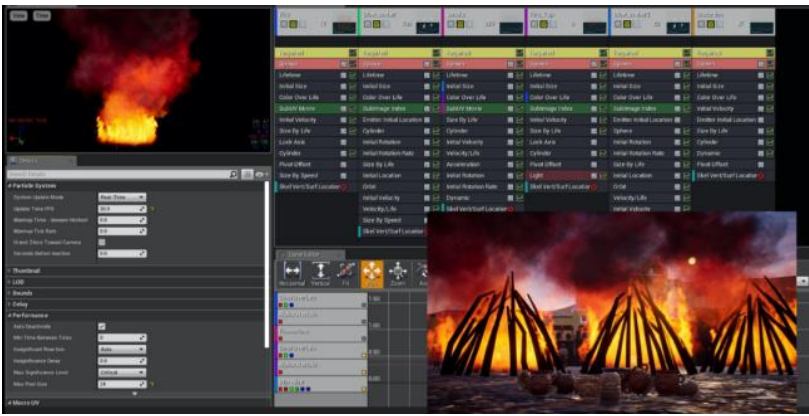

Figure. 3. Process of creating particles for the bonfires where more than 12,000 Maya idols were destroyed during the Great Auto de fe of 1554. Unreal Engine.

${ }^{5}$ Testimonio de Francisco de Figueroa sobre los autos de fe de los indios idolatras en Guatemala, 22 de enero 1565, AGI, Patronato 184, Exp. 52, 4 folios 


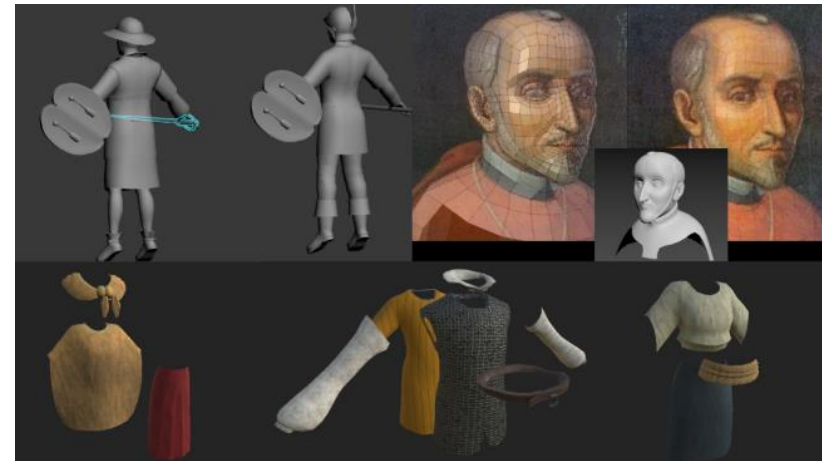

Figure. 4. Character development, including physical traits, costumes, accessories and in the case of Bishop Francisco Marroquín, his personal likeness.

4. A Navigation Team, which had the important task of designing the form of movement of the users, as well as the design of menus, callouts and welcome titles / credits (Figure 5).

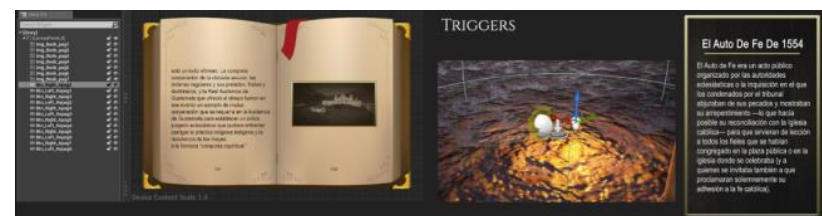

Figure. 5. Design of welcome menus and triggers to display posters with information about the buildings or processes present in the HRS.

Each team used core programs as illustrated below (Figure 6), but that did not mean that information was not shared or other programs were not used for support.

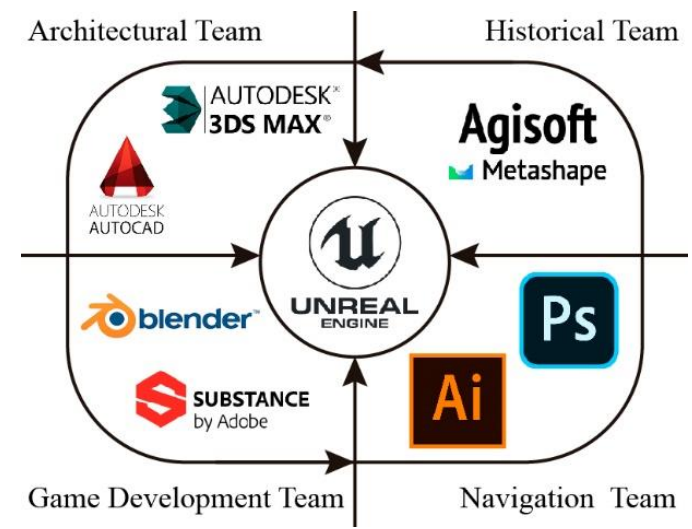

Figure 6. Team organization scheme

An important point was to decide the type of Discursive Model that would be used. Due to the nature of the historical event recreated, it was decided on a HRS that described the harshness of the event, but qualifying some of its most violent features: the "didactic theater" performed by Bishop Marroquín was not recreated, nor was any interactivity designed with whips, weapons or any other visual violence done to the avatars of indigenous Maya people. It was decided instead to include interactivity with models of the "idols" or god images destroyed in the bonfires that were arranged in the center of the square, as well as call-outs with relevant information about buildings in the plaza of Santiago, or detailed descriptions of various elements of the staging.

The testing phase was carried out intensively given the tight delivery schedule. It was decided to use a wired HTC Vibe Pro along with a Gamer grade PC Laptop. The dilemma of opting for navigation with controlled jumps or with dynamic routes was solved when verifying some dizziness effects when using the latter modality.

It was decided to create a pre-awareness sensitivity room with navigation instructions, a brief description of the historical event, and a panel with the project credits (Figure 7).

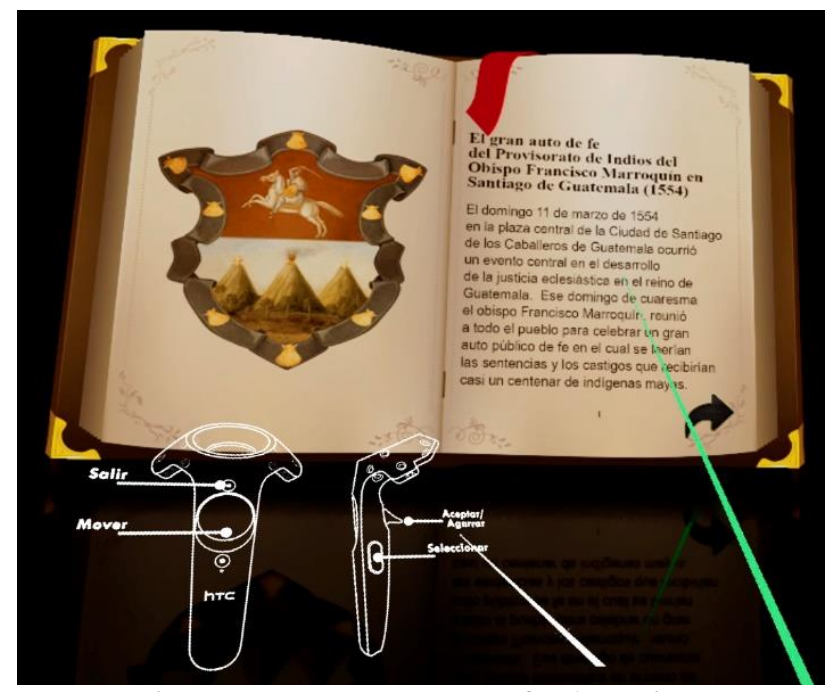

Figure 7. Pre-awareness room for the project.

Once inside the HRS, an exit point was designed that would allow the complete route from one end of the square and naturally induce the user to approach the bonfire and finally the stage in front of the Cathedral (Figure 8).

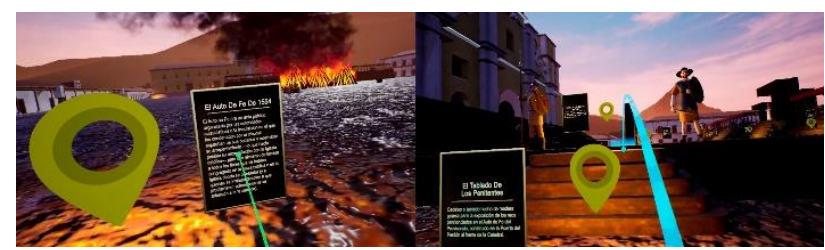

Figure 8. Aspects of the Plaza and the Staging.

The interactivity of the stage was limited to interacting with a sample of the archaeological pieces that were physically exhibited in the museum, allowing users to take them and instructing them to throw them on the bonfire like a Maya penitent would have been forced to do. Interior lights indicated those that were possible to grab in the scenario (Figure 9).

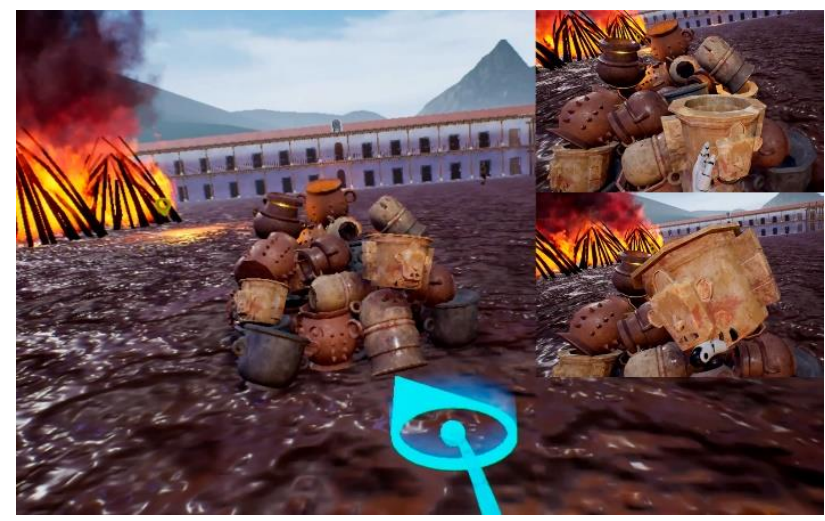

Figure 9. Pile of "idols" or god images in center of the plaza. 
On the stage, the most important reconstructed piece of the project, it was decided to place more call-outs explaining its different parts, the characters involved and the soundtrack of the chanted Iudica me Deus ["Judge me my God."] (Psalm 43), which according to the historical descriptions, was the song that accompanied the process of the Auto de Fe (Figure 10).

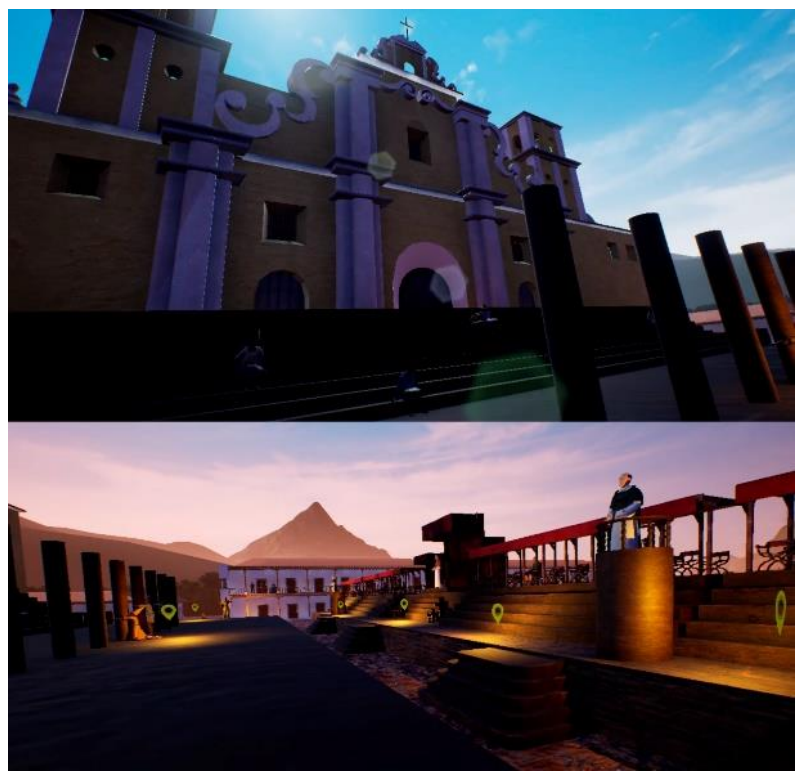

Figure 10. Aspects of the staging for the penitents.

\subsection{The exhibition. Reactions, surprises, resistances.}

The VR HRS was exhibited to the public in conjunction with the museum exhibit entitled "The images of the Maya gods in the 16th century: The Meeting of two Worlds", located at the Centro de Cooperación Española in Antigua, Guatemala, in a former Jesuit College, on two occasions: July 2019 and February 2020. A VR Booth was established at the end of the second showroom, where the available space was organized with a small waiting room and a dividing partition to allow individual access for users (Figure 11). Due to the high demand, each one had three minutes to tour the HRS, which at first raised doubts about its effectiveness as it was a very short time. However, the previously tested navigation proved to be effective and easy to learn, in addition to the limited dimensions of the HRS, which made it unnecessary to increase the time per user.

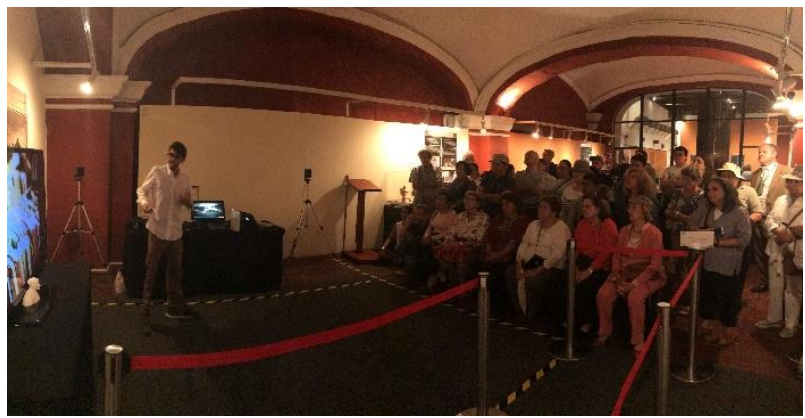

Figure 11. Instruction session prior to the VR experience for a group. The access control partitions and the delimitation of the playing area can be observed, as well as a monitor for the viewing of "passive players."

Accessibility was an issue that was not previously tested; however, actually our first user when opening the exhibition (since the exhibition of archaeological pieces and VR World was launched simultaneously), was a person in a wheelchair (Figure 12). Another user volunteered, at our suggestion, to support her with the rotational movements, in such a way that the user traveled the world with the handlers jumping and interacting in a fluid way.

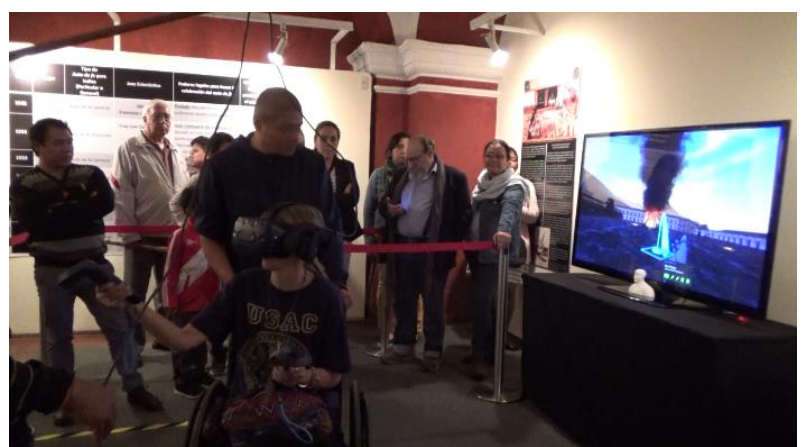

Figure. 12. A disabled person enjoying the experience. She received assistance for rotational movements, being able to control jumps and interactivity with objects.

It was interesting to note how the reactions and mastery of the HRS by users varied depending on their age, previous familiarity with computers or mobile devices, and even, without having specific measurements to prove it, on their ethnic group of origin. We can postulate that the group of users for whom the experience was most emotionally significant were the descendants of the Kaqchikel and Quiche Maya people. In general, these users refused to interact with the "idols" by "destroying" them at the bonfire (rather they deposited them at the feet of the Indigenous avatars in mourning for their destruction), or they gave adverse reactions to the colonial authorities located on the stage. On the other hand, users of mestizo, Creole or Hispanic descent weighed the technological features of the installation, the realism of the HRS, or appreciated the morphological differences of the Plaza with the buildings of today.

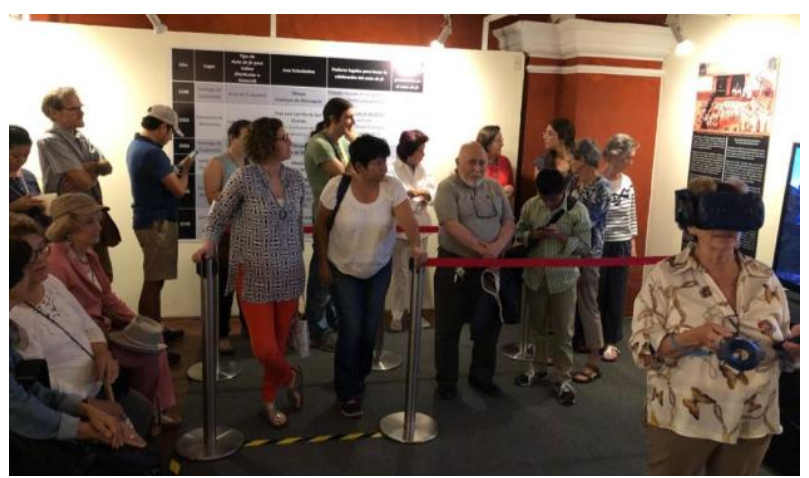

Figure. 13. A group of users waiting for their turn. July 16, 2019

The issue of the age of the users was surprisingly not a limiting factor. We had users from the ages of 7 to 80 years of age and in practically all cases there was no rejection of the experience, with various nuances of reactions (Figure 13). Younger users absorbed the immersion almost immediately and wanted to speed through the details of the stage (as beta testers, Figure 14), while older users focused on the details, stopping to read the callouts scattered around the square making reflections at the moment on the historical fact while they crossed it. Likewise, the historically empathic reactions of the users were significant who, when they finished testing the HRS experience, looked again at the archaeological pieces with different eyes, since they had virtually 
held them in their hands and had been asked to "destroy" them in a controlled simulation (on defining the use and application of VR for empathy see Liu, 2020, 189-191). They now appeared to recognize the character of the objects of cultural heritage as surviving pieces of sacred art, now understanding the significance of them having escaped being destroyed through a series of historical processes. It appeared that many had come to appreciate the nature of the clash of cultures inherent in colonialism in Guatemala, as even members of non-Indigenous groups appeared to come away with more empathy for the objects and the Indigenous people who suffered during the Auto de fe.

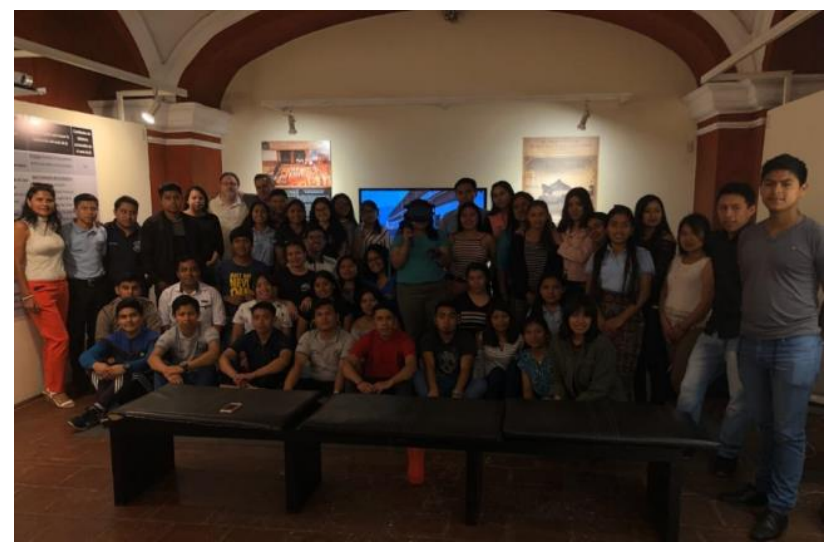

Figure. 11. A group of students on a guided visit to the simulation.

\subsection{Application and use of Satisfaction Surveys}

Thanks to the application of a post-visitor experience survey, a compendium of diverse data was generated with immediate and pure results. These were made up of men and women from advanced ages to minors, who participated with enthusiasm and acceptance of the experience, and in many cases this was their first interaction with VR. The key questions that were asked focused on taste, personal perceptions and an opinion on the exploitation and dissemination of this virtual medium for history works, generating a compendium of 213 opinions from users of the approximately 250 who in total had access to the survey. In order to obtain answers with maximum veracity (avoiding interactions with interviewers), it was decided to install an easily accessible iPad device at the exit of the experience area that allowed users to voluntarily interact with it and answer with full autonomy.

Broadly speaking, it was possible to verify an interest in continuing to test various experiences of historical context and VR applications in museums. Due to the possible consequences of dizziness caused by the excessive use of VR in very dynamic cases, it was decided to analyze whether the person, after using the viewer (5-7 min.), experienced physical discomfort; it was found that only $9.4 \%$ had mild discomfort, but nothing excessive that could cause disorientation or a negative experience. Thus, the success in the navigation strategy of the VR HRS is confirmed, preferring Warp jumps to continuous movement.

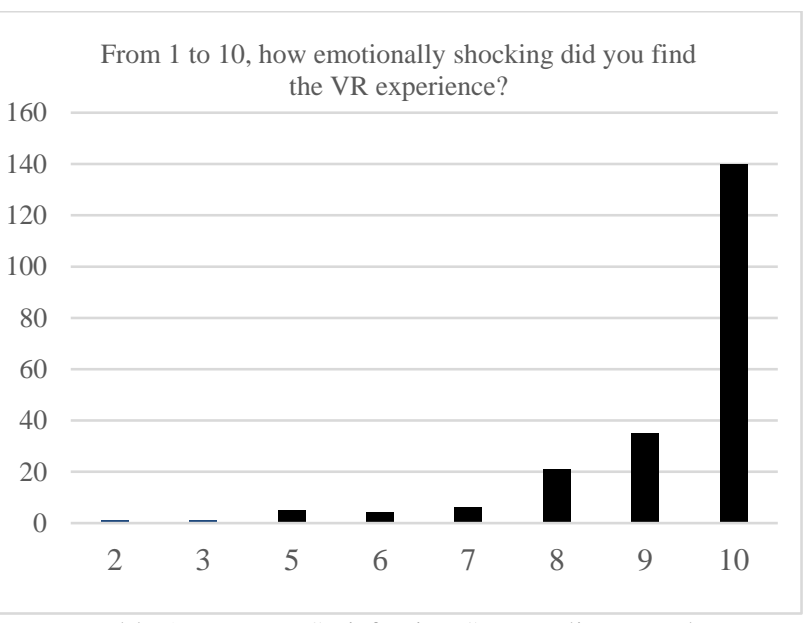

Table 1. VR user Satisfaction Survey, linear scale.

One of the objectives of the project was to find a response to the possibilities of emotional impact and perception of people to the most important and controversial historical events. This led to a satisfactory compendium of impact evaluation with diverse results and high-interest comments, on average above $90 \%$ acceptance (Table 1). In addition to the responses based on linear or Likert scales, some of the free comments written by users included:

-"Excellent experience. I think it is a learning tool. "

- "I really liked the experience in VR, I found it shocking how they caged people and forced them to do sad things (Dante, 7 years old)".

- "It would be great in the future to hear the voices of the characters, how did they speak?"

- "It is important for future generations to know the environments of that time."

- "My only constructive criticism would be to use a more impressive soundtrack and more sounds."

- "More equipment was needed to be able to spend more time going through the experience".

\subsection{The Aftermath: Projects Inspired by the Exposition}

The installation of the archaeological and VR exhibition, based on the analysis of the main organizers, proved to be the most successful of its kind to date in the country, in addition to being the first time that an Auto de fe (or act of faith) from colonial times in America has been shown in Virtual Reality. Various journalistic or electronic media notes replicated or glossed the HRS experience, providing their own data and interpretations (Figure 15). This revealed the major local impact that the simulation had in Guatemala.

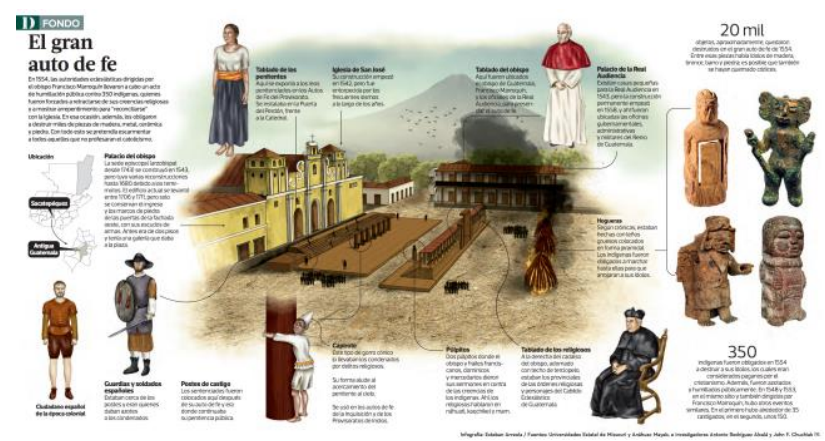

Figure. 15. Ilustrations created based on the HRS. Revista Prensa Libre, No. 784, Guatemala, August 18, 2019. 
The team is currently working on the HTML version of the HRS, so that it can be visited by any user, even on mobile devices (Figure 16). It is planned to include a previous selection of characters, so that even the gameplay will be affected depending on the type of character chosen in order to create historical empathy by revealing aspects of the effects of colonialism on Indigenous peoples.

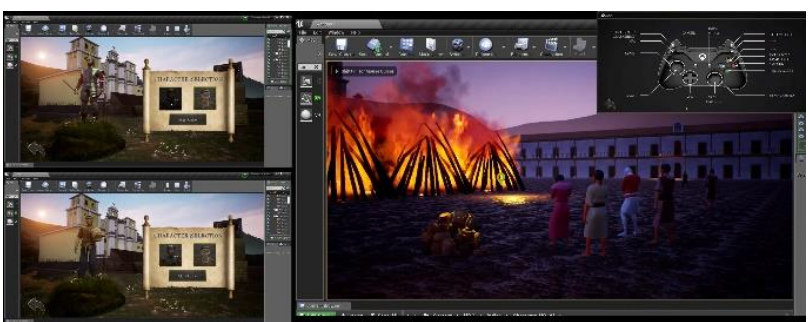

Figure 16. HTML version of the Scenario, with character selection option.

\subsection{The Making of a Mesoamerican Museum of the Exposition}

One way to contribute to the Auto de Fe exhibit was to create an exhibition of Mesoamerican cultural and historical artifacts in virtual space in a manner that they could be observed and studied worldwide even after the exposition ended in March, 2020. We had full access to more than 200 exhibited pieces and due to schedule and time constraints, the photogrammetry process was made on-the-go, as the exhibit was still running (Figure 17).

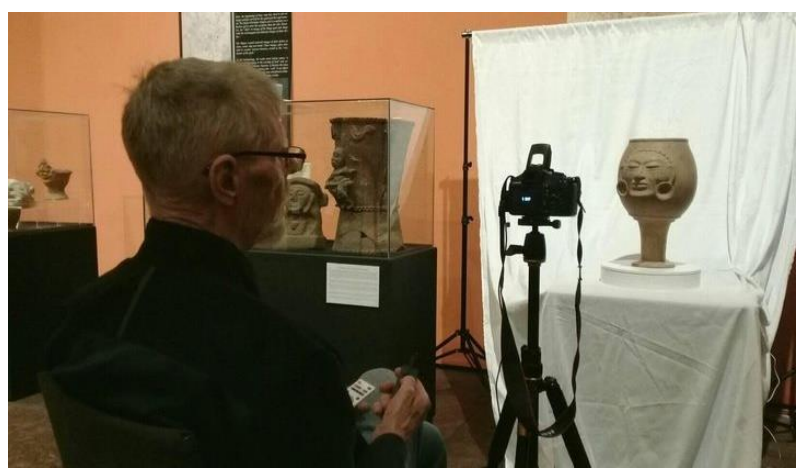

Figure 17. Photogrammetric capture process of the exhibited pieces by using the ComXim Professional 360 Degree photography turntable, Cannon Rebel EOS T3 with shutter remote control and portable sets of lights and backdrops.

For the most part the researcher Hans Erickson took an average of 125 to 150 photos of each artifact in as many positions as possible. If the artifact had an interior surface it was attempted to illuminate and photograph the interior as well. For a semiautomatic masking process, he used the automatic IA function in Photoshop to achieve this effect and ran all the photographs as a batch function. This was not foolproof, but Photoshop ${ }^{\oplus}$ produced clear masked out photos over 95 percent of the time (Figure 18).

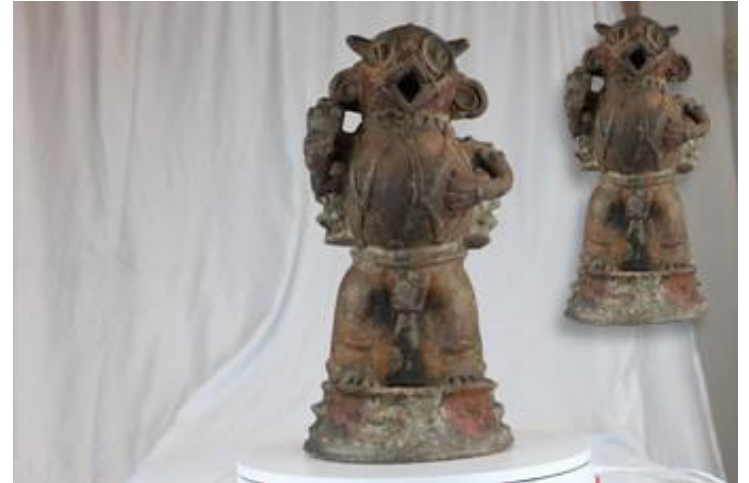

Figure 18. Raw and masked images of a character with bird mask.

For the 3D processing software Agisoft Metashape $^{\odot}$ was addressed. The processed mesh is generally worth 80,000 to 180,000 faces per artifact. For the purposes of using this mesh in a game engine for Virtual Reality or First-person shooter, those face counts were much too high. It was necessary to reduce the face count but preserve the detail as much as possible. This was achieved through a 3D software application Blender $^{\odot}$ in this case). Once the OBJ file for the mesh and the diffuse color map is imported into Blender ${ }^{\odot}$ it was necessary to resize the mesh to the correct dimensions of the physical artifact and to duplicate the mesh. The first copy was labeled by its artefact control number and with a subscript of either being high or low resolution. The mesh labeled "artifact_low" was then decimated to reduce the face count to around $9, \overline{000}$ faces. It was necessary at that point to produce a new UV map and material for that mesh and to bake a new diffuse color map from the high-resolution mesh to the low-resolution mesh. The new color map was then saved and both the high and low resolution meshes were then exported out as FBX files for the next process.

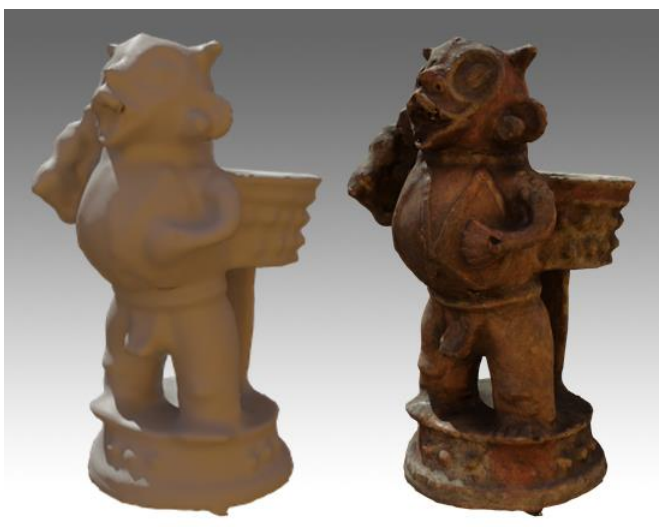

Figure 19. Raw and textured mesh.

Substance Painter ${ }^{\oplus}$ was then employed to complete the texture maps to produce a final high-quality mesh in 3D. The lowresolution mesh and the diffuse color map were imported into Substance Painter ${ }^{\odot}$ and additional texture maps were then baked out against the high resolution FBX file. The final texture map to be produced was the roughness map which was produced by using a sand filter since most of the artifacts were clay ceramic based. These texture maps were then exported out for use again in Blender $^{\oplus}$ and $\mathrm{UE}^{\odot}$. The texture maps were applied to the lowresolution mesh in Blender $^{\odot}$ and the virtual camera was set up for high quality renders of each artifact for both stills and a short rotating animation of each artifact (Figure 19). 
For the process of making the virtual venue for the placement of all those virtual pieces, Blender and Unreal Engine from Epic Games were leveraged to re-create the space for the exhibit. We were given the architectural plans of the facilities and with onsite measurements from which we were able to construct the main patio and rooms where the event was held again using photographic references as a guide for materials and textures (Figures 20, 21).

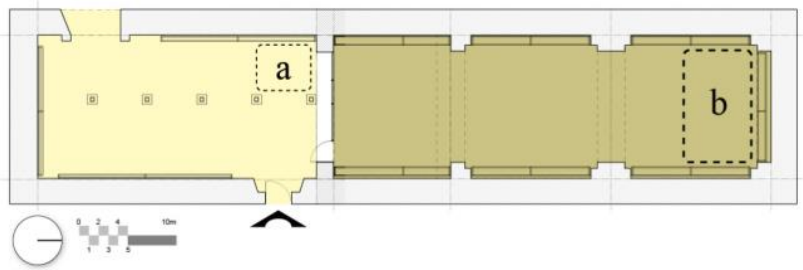

Figure 20. Architectural plan of the exhibition room. a.Photogrammetry Station; b.- VR Booth.

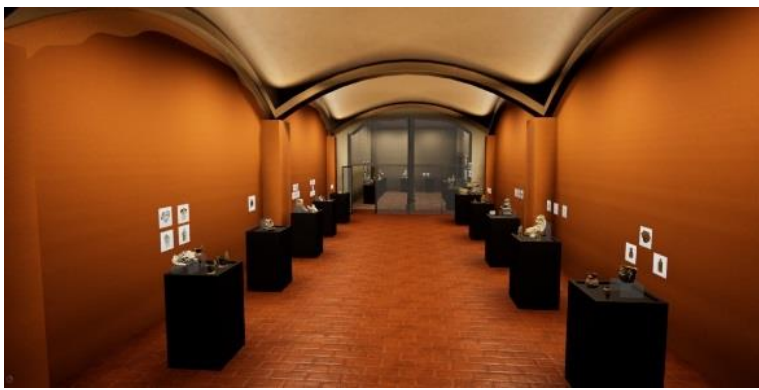

Figure 21. Screen caption of the Virtual Museum with the pieces registered with photogrammetry.

\section{CONCLUSIONS}

The experience with the Historically Reconstructed Scenario (HRS) of the Auto de Fe allowed us to test a workflow based on the previous and acquired knowledge on the progress of a work team seriously committed to the project. However, the most important thing was to observe the reactions of the various groups of users who had access to the experience, since it was they who really validated the project, its successes and its areas of opportunity or aspects for improvement. Their historically empathetic responses to their own archaeological heritage became significant for future work in framing the remains of their cultural heritage in hypothetical reconstruction scenarios. Likewise, thanks to the results of the survey and the emotional impact analysis items, we were able to understand how a format without movement dynamics in characters or direct interaction would cause less adverse reactions in users, being a more inclusive option. This feedback leaves us with speculations on how an even more refined experience can achieve a higher level of historical empathy and impact achievements.

The design of the Discursive Model will continue to be the key factor to consider for future experiences, since it is necessary to reflect not only on the materiality of the facts and the objects, but also on the sensitivity of the users for whom the project will be oriented.

\section{ACKNOWLEDGEMENTS}

To the students providing social services at the Universidad Anáhuac Mayab who contributed greatly to the realization of the project: Héctor Parra, Julio Cadena, Edson Garrido, Mario Vallarta, Ángela Tovar and Carlos Basto; Professors Mauricio Palacios and José Luis Barrera; and we want to acknowledge the work of José Peñalonzo and the entire team at the Centro de la Cooperación Española in Antigua, Guatemala; and finally Sofía Paredes Maury from La Ruta Maya Foundation, Guatemala; and the generous sponsors of the exhibit.

\section{REFERENCES}

D. Aiello, S. Fai, C. Santagati (2019). ISPRS-Archives VIRTUAL MUSEUMS AS A MEANS FOR PROMOTION AND ENHANCEMENT OF CULTURAL HERITAGE. Digital Object Identifier System. https://doi.org/10.5194/isprs-archives-XLII2-W15-33-2019

S. Chiarenza, A.R.D. Accardi, R. Inglisa (2019). ISPRS-Archives TECHNOLOGICAL INNOVATION AND NEW PRESENTATION STRATEGIES FOR VIRTUAL MUSEUM EXHIBITIONS. Digital Object Identifier System. https://doi.org/10.5194/isprs-archives-XLII-2-W15311-2019

Y. Liu (2020) THE APPLICATION OF VIRTUAL REALITY IN EMPATHY ESTABLISHMENT: FORESEE THE FUTURE, Digital Object Identifier System https://doi.org/ 10.1109/ICCIA49625.2020.00043

K. Pavelka Jr., P. Raeva (2019). ISPRS-Archives - VIRTUAL MUSEUMS - THE FUTURE OF HISTORICAL MONUMENTS DOCUMENTATION AND VISUALIZATION. Digital Object Identifier System. https://doi.org/10.5194/isprs-archives-XLII2-W15-903-2019

P.A. Rufino, D. Permadi et al. (2019). ISPRS-Annals - DIGITAL TECHNOLOGIES FOR INCLUSIVE CULTURAL HERITAGE: THE CASESTUDY OF SERRALUNGA D'ALBA CASTLE. Digital Object Identifier System. https://doi.org/10.5194/isprsannals-IV-2-W6-141-2019

J. Santacana, T. Martínez (2018). El patrimonio cultural y el sistema emocional: un estado de la cuestión desde la didáctica| Santacana Mestre | Arbor. Digital Object Identifier System. https://doi.org/10.3989/arbor.2018.788n2006

H. Shim, J.Y. Jun, J. Ahn (2019). ISPRS-Archives PERSONALIZATION ENVISAGED IN MUSEUM APPLICATION GUIDES AND THEIRIMPLICATIONS: UNDERSTANDING THE CONTEXTUALIZATION OF THE VIRTUALMUSEUM WITHIN THE MUSEUMS OF KOREA. Digital Object Identifier System. https://doi.org/10.5194/isprsarchives-XLII-2-W15-1089-2019

The London Charter for the Computer Based Visualisation of Cultural Heritage (2009). Available at $<$ http://www.londoncharter.org/>

White, R. (2010). What is Spatial History? Stanford University. Available at https://web.stanford.edu/group/spatialhistory/cgibin/site/pub.php?id=29

\section{APPENDIX}

Original satisfaction survey applied to attendees: https://forms.gle/481RhKqZLMgbFaUG8

$3 \mathrm{~d}$ views of some of the scanned parts in the exhibit: https://p3d.in/u/hansberickson/abc 